\title{
PROTECCIÓN Y BIENESTAR DE LOS NIÑOS PRIVADOS DEL CUIDADO PARENTAL O EN PELIGRO DE ENCONTRARSE EN ESA SITUACIÓN
}

María Isabel Sokolich Alva ${ }^{1}$

\section{INTRODUCCIÓN:}

A finales del año 2016, el Gobierno promulgó diversos Decretos Legislativos orientados a la reactivación de la economía y seguridad ciudadana; es así que se expide el Decreto Legislativo N. ${ }^{\circ} 1297$ por el cual se regula la protección de las niñas, niños y adolescentes sin cuidados parentales o en riesgo de perderlos.

La norma en su exposición de motivos parte por reconocer la especial protección que merece la familia, lo cual es relevante destacar pues aquella es la cuna de formación de la persona humana en principios, valores y respeto de las normas sociales.

Lastimosamente, en la actualidad muchas familias se encuentran en crisis por diversos factores, entre los cuales se puede distinguir violencia doméstica, falta de comuni- cación entre sus miembros, consumo de alcohol y drogas, promiscuidad y precocidad sexual, incumplimiento de la responsabilidad parental, deserción escolar, etc, lo que de no ser atendido en forma seria, responsable y oportuna fácilmente puede dar lugar a problemas sociales graves como feminicidio, desprotección familiar, delincuencia juvenil, etc, lo que incrementa el clima de inseguridad ciudadana.

El Decreto Legislativo N. ${ }^{\circ} 1297$ justamente identifica la desprotección familiar de los niños, niñas y adolescentes como una de las causas u origen de la delincuencia juvenil, de allí la necesidad de prevenirla y afrontarla a través de un sistema de protección integral. Ello es de especial relevancia, pues concreta el compromiso del Estado y la comunidad, plasmado en el artículo $4 .^{\circ}$ de la Norma Fundamental, de proteger especialmente a los niños ${ }^{2}$ por medio de políticas públicas reales y efectivas.

Resulta oportuno, destacar, además, que la norma se sustenta en las "Directrices sobre las modalidades alternativas de cuidado de los niños", aprobadas por la Asamblea General de las Naciones Unidas en su sexagésimo cuarto período de sesiones, en el marco de las celebraciones del vigésimo aniversario de la Convención sobre los Derechos del Niño, realizado en el año 2009.

Dichas directrices, conforme así se establece en su Preámbulo, además de reafirmar la relevancia de la Declaración Universal de Derechos Humanos y la Convención sobre los Derechos del Niño, y, por tanto, el rol de garante de los Estados, establecen las pautas a observar en aras de promover la aplicación de la Convención sobre los Derechos del Niño

Doctora en Derecho por la Universidad San Martín de Porres. Magíster en Derecho Civil con mención en Derecho de Familia por la Universidad Femenina del Sagrado Corazón. Fiscal Adjunto Supremo de la Fiscalía Suprema Civil. Docente de la Maestría de Derecho Civil con mención en Derecho de Familia de la Universidad Femenina del Sagrado Corazón -UNIFE-, así como de la Maestría de Derecho de Persona, Matrimonio y Familia de la Universidad Católica Santo Toribio de Mogrovejo. Docente de la Academia de la Magistratura en la especialidad de Derecho de Familia. Autora del libro "Violencia Familiar” y de diversos artículos jurídicos de la especialidad. Expositora en diversos eventos académicos relacionados con el Derecho de Familia.

2 Para el análisis utilizaremos solo los términos “niño" y “niños”; sin embargo, entiéndase también comprendidos las niñas y adolescentes. 
y las disposiciones pertinentes de otros instrumentos internacionales referentes a la protección y bienestar de los niños privados del cuidado parental o en peligro de encontrarse en esa situación.

Es importante resaltar que el Decreto Legislativo N. ${ }^{\circ} 1297$ si bien deroga diversos artículos del Código de los Niños y Adolescentes (artículos $45 .^{\circ}$ literal d), $104 .^{\circ}, 105 .^{\circ}, 106 .^{\circ}$, $107 .^{\circ}, 108 .^{\circ}, \quad 117 .^{\circ}, 120 .^{\circ}$, $121 .^{\circ}, 122 .^{\circ}, 123 .^{\circ}, 124 .^{\circ}$, $125 .^{\circ}, 126 .^{\circ}, 129 .^{\circ}, 1300^{\circ}$, $243 .^{\circ}, 244 .^{\circ}, 245 .^{\circ}, 246 .^{\circ}$, $247 .^{\circ}, 248 .^{\circ}, 249 .^{\circ}, 2500^{\circ}$, $251 .^{\circ}$ y $252 .^{\circ}$ ), Código Civil (artículo $511 .^{\circ}$ ) y leyes como las referentes al Acogimiento $\mathrm{Fa}$ miliar (Ley N. ${ }^{\circ} 30162$ ), Ley General de Centros de Atención Residencial de Niñas, Niños y Adolescentes (Ley N. ${ }^{\circ}$ 29174), Ley que Protege a los Menores de Edad de la Mendicidad (Ley N. ${ }^{\circ} 28190$, artículos $1 .^{\circ}$, $2 .^{\circ}, 3 .^{\circ}$ y $4 .^{\circ}$ ) y Ley de Proce- dimiento Administrativo de Adopción de Menores de Edad Declarados Judicialmente en Abandono (Ley $\mathrm{N}^{\circ}$ 26981), a la fecha no se encuentra vigente conforme lo dispuesto por la Primera y Segunda Disposición Complementaria $\mathrm{Final}^{3}$, al encontrarse pendiente su Reglamento, el cual deberá ser expedido por el Ministerio de la Mujer y Poblaciones aproximadamente a fines de abril de este año ${ }^{4}$.

\section{ANTECEDENTES:}

El Código de los Niños y Adolescentes y leyes complementarias como las antes mencionadas, han venido regulando en forma aislada diversos aspectos vinculados con la situación de desprotección familiar en la que se encuentran muchos niños del país.

De esta forma, tenemos por ejemplo, la prerrogativa reconocida a las Defensorías de co- nocer casos de "colocación familiar" 5 , conforme lo prescrito por el literal d) del artículo 45. ${ }^{\circ}$ del Código de los Niños y Adolescentes $^{6}$.

La colocación familiar es una medida de protección que consiste en la entrega de un niño a una persona, familia o institución con la finalidad de resguardar su integridad ante la ausencia de sus padres, desconocimiento de su paradero, 0 , incumplimiento de roles.

Se entiende que la colocación familiar es una medida de protección provisional que se mantiene hasta que la situación familiar que dio origen a la separación del niño de su entorno familiar haya sido superada; sin embargo, a tenor de lo dispuesto por el literal c) del artículo $128 .^{\circ}$ del Código de la especialidad ${ }^{7}$, posibilita el proceso de adopción por excepción.

3 PRIMERA. - Vigencia de la Ley

La presente Ley entra en vigencia a partir del día siguiente de la publicación de su reglamento.

SEGUNDA.- Reglamentación

El Ministerio de la Mujer y Poblaciones Vulnerables, reglamenta la presente Ley en un plazo de ciento veinte (120) días y dicta las disposiciones legales que sean necesarias para la aplicación de la presente norma.

4 Conforme a la norma, el reglamento debe expedirse a los 120 días de publicación del Decreto Legislativo, que data del 30 de diciembre de 2016

5 Denominada “Acogimiento Familiar” por la Tercera Disposición Complementaria Final de la Ley 30162, derogada a su vez por la Primera Disposición Complementaria del Decreto Legislativo N. ${ }^{\circ} 1297$; no obstante, aún vigente por imperio de la Primera Disposición Complementaria Final de la misma ley

6 Artículo 45.- Funciones específicas.-

Son funciones de la Defensoría:

a) Conocer la situación de los niños y adolescentes que se encuentran en instituciones públicas o privadas;

b) Intervenir cuando se encuentren amenazados o vulnerados sus derechos para hacer prevalecer el principio del interés superior;

c) Promover el fortalecimiento de los lazos familiares. Para ello puede efectuar conciliaciones extrajudiciales entre cónyuges, padres y familiares, sobre alimentos, tenencia y régimen de visitas, siempre que no existan procesos judiciales sobre estas materias;

d) Conocer de la colocación familiar; (...)

7 Artículo 128.- Excepciones.-

En vía de excepción, podrán iniciar acción judicial de adopción ante el Juez especializado, inclusive sin que medie declaración de estado de abandono del niño o del adolescente, los peticionarios siguientes:

a) El que posea vínculo matrimonial con el padre o madre del niño o el adolescente por adoptar. En este caso el niño o adolescente mantienen los vínculos de filiación con el padre o madre biológicos;

b) El que posea vínculo de parentesco hasta el cuarto grado de consanguinidad o segundo de afinidad con el niño o adolescente pasible de adopción; y

c) El que ha prohijado o convivido con el niño o el adolescente por adoptar, durante un período no menor de dos años. 
Esta es la razón por la cual los artículos $45 .^{\circ}$ literal d), $128 .^{\circ}$ literal c) y $243 .^{\circ}$ del Código de los niños y Adolescentes han sido derogados por el Decreto Legislativo N. ${ }^{\circ} 1297$, pues lo que se pretende es canalizar en un solo procedimiento la atención y medida de protección a otorgar un niño que se encuentra en riesgo o desprotección familiar.

Es de notar, que conforme al mencionado artículo $243 .^{\circ}$ del Código de los niños y Adolescentes, la colocación familiar igualmente resulta aplicable por el Ministerio de la Mujer y Poblaciones Vulnerables como medida de protección a favor de un niño en presunto estado de abandono ${ }^{8}$.
El estado de "abandono", conforme la regulación recogida por el aún vigente artículo $248 .^{\circ}$ del Código de los Niños y Adolescentes $^{9}$, ha dado paso a lo que ahora se entiende como "desprotección familiar", que conforme al Decreto Legislativo N. ${ }^{\circ} 1297$, es el resultado del incumplimiento o inadecuado desempeño de los deberes de cuidado y protección por parte de los responsables de los niños, hecho que afecta gravemente su desarrollo integral.

Como es de colegir, se alude al incumplimiento de la responsabilidad parental que conforme al artículo $6 .^{\circ}$ de la Constitución Política del Estado ${ }^{10}$, implica la obligación que tiene tanto el padre como la madre de velar por el adecuado proceso de crianza y desarrollo de sus hijos con la finalidad de lograr su desarrollo holístico.

El artículo $74 .^{\circ}$ del Código de los Niños y Adolescentes regula diversos deberes y derechos de la patria potestad, ${ }^{11}$ entre ellos, proveer su sostenimiento y educación, dirigir su proceso educativo, tenerlos en su compañía, etc.

La Convención sobre los Derechos del Niño por el artículo $3 .^{\circ}$, además de consagrar en su primer párrafo el "Principio del Interés Superior del Niño",

8 Artículo 243.- Protección

El Ministerio de la Mujer y Desarrollo Social podrá aplicar al niño y al adolescente que lo requiera cualquiera de las siguientes medidas de protección:

a) El cuidado en el propio hogar, para lo cual se orientará a los padres, familiares o responsables en el cumplimiento de sus obligaciones, contando con apoyo y seguimiento temporal por instituciones de defensa;

b) La participación en el Programa Oficial o Comunitario de Defensa con atención educativa, de salud y social;

c) Incorporación a una familia sustituta o colocación familiar;

d) Atención integral en un establecimiento de protección especial debidamente acreditado; y,

e) Dar en adopción al niño o adolescente, previa declaración del estado de abandono expedida por el Juez especializado."

9 Artículo 248.- Casos.-

El Juez especializado podrá declarar en estado de abandono a un niño o adolescente cuando:

a) Sea expósito;

b) Carezca, en forma definitiva, de las personas que conforme a la ley tienen el cuidado personal de su crianza, educación 0 , si los hubiera, incumplan las obligaciones o deberes correspondientes; o carecieran de las calidades morales o mentales necesarias para asegurar la correcta formación;

c) Sea objeto de maltratos por quienes están obligados a protegerlos o permitir que otros lo hicieran;

d) Sea entregado por sus padres a un establecimiento de asistencia social público o privado y lo hubieran desatendido

injustificadamente por seis meses continuos o cuando la duración sumada exceda de este plazo;

e) Sea dejado en instituciones hospitalarias u otras similares con el evidente propósito de abandonarlo;

f) Haya sido entregado por sus padres o responsables a instituciones públicas o privadas, para ser promovido en adopción;

g) Sea explotado en cualquier forma o utilizado en actividades contrarias a la ley o a las buenas costumbres por sus padres o responsables, cuando tales actividades sean ejecutadas en su presencia.

h) Sea entregado por sus padres o responsables a otra persona mediante remuneración o sin ella con el propósito de ser obligado a realizar trabajos no acordes con su edad; y

i) Se encuentre en total desamparo.

La falta o carencia de recursos materiales en ningún caso da lugar a la declaración del estado de abandono.

10 Artículo 6.- La política nacional de población tiene como objetivo difundir y promover la paternidad y maternidad responsables. Reconoce el derecho de las familias y de las personas a decidir. En tal sentido, el Estado asegura los programas de educación y la información adecuados y el acceso a los medios, que no afecten la vida o la salud.

Es deber y derecho de los padres alimentar, educar y dar seguridad a sus hijos. Los hijos tienen el deber de respetar y asistir a sus padres.

Todos los hijos tienen iguales derechos y deberes. Está prohibida toda mención sobre el estado civil de los padres y sobre la naturaleza de la filiación en los registros civiles y en cualquier otro documento de identidad.

11 Lo correcto es aludir a "responsabilidad parental", pues el artículo $18 .^{\circ}$ de la Convención sobre los Derechos el Niño reconoce a ambos padres la obligación de criar a sus hijos, lo cual resulta compatible con la noción de coparentalidad. 
inmediatamente subraya la obligación que tienen los Estados de asegurarles protección y cuidado, teniendo en cuenta los derechos y deberes de los padres, tutores u otros responsables, de tal forma que el niño no debe ser separado de sus padres, salvo que dicha medida se sustente en garantizar su bienestar, como sucedería en supuestos de maltrato, descuido, perjuicio, abuso, descuido, trato negligente, explotación, etc.

En situaciones como las descritas se justifica la intervención estatal mediante acciones administrativas y judiciales adecuadas que garanticen la protección del niño, conforme lo dispuesto por los artículos $9 .^{\circ}$, $19 .^{\circ}$ y $20 .^{\circ}$ de la Convención ${ }^{12}$. Este es la razón de ser del Decreto Legislativo N. ${ }^{\circ} 1297$, pues conforme a su artículo $1 .^{\circ}$ la finalidad es la protección integral de las niñas, niños y adolescentes sin cuida- dos parentales o en riesgo de perderlos a fin de garantizarles el pleno ejercicio de todos sus derechos, sobretodo el vivir, crecer y desarrollarse en el seno de su familia

Ahora bien, el literal g) del artículo $3 .^{\circ}$ del citado Decreto Legislativo establece que la situación de "desprotección familiar" tiene carácter provisional e implica la separación temporal de la niña, niño o adolescente de su familia para su protección, así como el apoyo especializado a la familia para la remoción de las circunstancias que la motivaron; sin embargo, el artículo $92 .{ }^{\circ}$ de la misma norma regula la potestad de la autoridad administrativa de promover la respectiva declaración judicial de desprotección familiar cuando del seguimiento y evaluación del plan de trabajo individual se determine que no existe posibilidad de reintegración del niño a su entorno familiar o resulte contrario a su interés superior.

Es importante resaltar, que la decisión administrativa debe tomar en cuenta la opinión del niño y sustentarse tanto en su interés superior como en los principios de necesidad e idoneidad. Ello resulta positivo, pues se materializa en la práctica las Observaciones Generales del Comité de los Derechos del Niño N. ${ }^{\circ} 12$ (2009) y $14(2013) .^{13}$

Los supuestos que pueden dar lugar a la declaración de desprotección familiar deben ser desarrollados por el Reglamento; no obstante, en ningún caso la pobreza ni la discapacidad del niño o de alguno de los miembros de su entorno familiar justifica por sí misma la separación del niño de su entorno familiar, lo cual también es relevante, pues resul-

12 Artículo 9

1. Los Estados Partes velarán por que el niño no sea separado de sus padres contra la voluntad de éstos, excepto cuando, a reserva de revisión judicial, las autoridades competentes determinen, de conformidad con la ley y los procedimientos aplicables, que tal separación es necesaria en el interés superior del niño. Tal determinación puede ser necesaria en casos particulares, por ejemplo, en los casos en que el niño sea objeto de maltrato o descuido por parte de sus padres o cuando éstos viven separados y debe adoptarse una decisión acerca del lugar de residencia del niño. (...)

Artículo 19

1. Los Estados Partes adoptarán todas las medidas legislativas, administrativas, sociales y educativas apropiadas para proteger al niño contra toda forma de perjuicio o abuso físico o mental, descuido o trato negligente, malos tratos o explotación, incluido el abuso sexual, mientras el niño se encuentre bajo la custodia de los padres, de un representante legal o de cualquier otra persona que lo tenga a su cargo.

2. Esas medidas de protección deberían comprender, según corresponda, procedimientos eficaces para el establecimiento de programas sociales con objeto de proporcionar la asistencia necesaria al niño y a quienes cuidan de él, así como para otras formas de prevención y para la identificación, notificación, remisión a una institución, investigación, tratamiento y observación ulterior de los casos antes descritos de malos tratos al niño y, según corresponda, la intervención judicial.

Artículo 20

1. Los niños temporal o permanentemente privados de su medio familiar, o cuyo superior interés exija que no permanezcan en ese medio, tendrán derecho a la protección y asistencia especiales del Estado.

2. Los Estados Partes garantizarán, de conformidad con sus leyes nacionales, otros tipos de cuidado para esos niños.

3. Entre esos cuidados figurarán, entre otras cosas, la colocación en hogares de guarda, la kafala del derecho islámi-

co, la adopción o de ser necesario, la colocación en instituciones adecuadas de protección de menores. Al considerar las soluciones, se prestará particular atención a la conveniencia de que haya continuidad en la educación del niño y a su origen étnico, religioso, cultural y lingüístico.

13 A nivel nacional el principio del interés superior del niño se recoge en el artículo IX del Título Preliminar del Código de los Niños y Adolescentes y en forma específica en la Ley N. ${ }^{\circ} 30466$. 
ta coherente con el reconocimiento del derecho del niño de desarrollarse en el seno de su propia familia, conforme así se destaca en el Preámbulo de la Convención sobre los Derechos del Niño.

\section{ASPECTOS SUSTANCIALES DEL DECRETO LEGISLATIVO N. ${ }^{\circ}$ 1297:}

A continuación, procederemos a analizar algunos de los aspectos más destacados de la norma:

\section{a) Principios orientadores de la actuación estatal:}

El artículo $4 .^{\circ}$ del Decreto Legislativo N. ${ }^{\circ} 1297$ puntualiza que son principios orientadores de la actuación estatal los siguientes: diligencia excepcional, especialidad y profesionalización, excepcionalidad y temporalidad, igualdad y no discriminación, informalismo, integración familiar, interés superior del niño, flexibilidad y gradualidad, necesidad e idoneidad, subsidiaridad progresiva de la actuación del Estado e interculturalidad.

Acorde a los citados principios, la valoración preliminar de la situación socio-familiar de un niño, así como los procedimientos por riesgo y desprotección familiar se deben caracterizar por lo siguiente: a) observancia del triple concepto del interés superior del niño, conforme a la Observación General N. ${ }^{\circ} 14$ del Comité de los Derechos del Niño ${ }^{14}$; b) prevalencia del derecho del niño a vivir, crecer y desarrollarse en el seno de su familia de origen y solo en casos extremos, decidir, como último recurso, la separación del niño del entorno familiar que resulta negativo para sus intereses y desarrollo; c) actuación pronta, responsable, especializada y libre de todo formalismo de la autoridad; d) otorgamiento de medidas de protección flexibles y acorde a cada caso en particular, las cuales deben ser supervisadas en forma constante a fin de verificar su efectividad; $y$, e) consideración y respeto de todos los derechos del niño reconocidos en el ordenamiento jurídico nacional y en los instrumentos internacionales de derechos humanos que resulten aplicables.

Es importante la mención de los citados principios; no obs- tante, consideramos que se han omitido dos principios igualmente relevantes como son: a) el derecho del niño a emitir opinión en todos los asuntos en los que se encuentre inmerso; y, b) la motivación y justificación de las decisiones estatales en el interés superior del niño. Si bien estos principios se desarrollan en diversos artículos del Decreto Legislativo ${ }^{15}$, al ser la fuente inspiradora y esencial de la actuación estatal era necesaria su inclusión en este acápite, más aún las exigencias del Comité de los Derechos del Niño materia de las últimas Observaciones finales al Estado Peruano sobre los informes periódicos cuarto y quinto de marzo de $2016{ }^{16}$, por las cuales se requiere, entre otros, el ejercicio efectivo del derecho del niño a emitir opinión.

b) Reconocimiento de los derechos de los niños, niñas y adolescentes en riesgo o desprotección familiar y de la familia de origen:

El artículo $5 .^{\circ}$ del Decreto Legislativo N. ${ }^{\circ} 1297$ establece la obligación de la autoridad estatal de velar por el ejercicio efectivo de los derechos de los

\footnotetext{
Derecho sustantivo, principio jurídico interpretativo fundamental y norma de procedimiento.

Artículos $5 .^{\circ}, 6 .^{\circ}, 7 .^{\circ}, 9 .^{\circ}, 28 .^{\circ}, 29 .^{\circ}, 50 .^{\circ}, 60 .^{\circ}, 66 .^{\circ}, 72 .^{\circ}, 83 .^{\circ}, 85 .^{\circ}, 92 .^{\circ}, 99 .^{\circ}$ y $138 .^{\circ}$.

16 32. Habida cuenta de su observación general núm. 12 (2009) sobre el derecho del niño a ser escuchado, el Comité recomienda al Estado parte que:

a) Adopte medidas concretas para tener en cuenta las opiniones expresadas por los niños en diversos foros en relación con todos los procesos de adopción de decisiones que les afecten;

b) Vele por que el derecho del niño a la participación en los asuntos pertinentes quede garantizado en la versión revisada del Código de los Niños y Adolescentes, de conformidad con el artículo 12 de la Convención;

c) Vele por la aplicación efectiva de la legislación que reconoce el derecho del niño a ser escuchado en las actuaciones judiciales pertinentes, lo que incluye el establecimiento de sistemas o procedimientos para que los trabajadores sociales y los tribunales se ajusten a ese principio;

d) Establezca programas y actividades de sensibilización para promover la participación real y efectiva de todos los niños dentro de la familia, la comunidad y la escuela, prestando especial atención a las niñas y a los niños y niñas en situaciones vulnerables;

e) Establezca directrices e indicadores para facilitar, evaluar y supervisar la aplicación del derecho del niño a participar en asuntos pertinentes y a ser escuchado en los procedimientos jurídicos y administrativos, y vele por que los profesionales pertinentes reciban formación sobre su utilización.

Niños privados de un entorno familiar.
} 
niños reconocidos en la legislación nacional; empero, obvia similar obligación respecto de los reconocidos en instrumentos internacionales de Derechos Humanos como la propia Convención sobre los Derechos del Niño y la Convención Americana de Derechos Humanos, entre otros, lo cual constituye una grave omisión, más aún que el Estado Peruano en atención a su calidad de garante tiene el deber de permitir, proteger y realizar en el país los derechos humanos que han sido materia de los tratados internacionales que ha suscrito y ratificado, más aún de los grupos poblacionales más vulnerables, como el conformado por los niños.

Sin perjuicio de lo expresado, resulta un acierto la materialización del reconocimiento del niño como "sujeto de derechos" cuando, por ejemplo, se establece que aquel tiene expeditos los siguientes derechos: a) mantener relaciones personales con su familia y otras personas cercanas como amigos o vecinos; b) gozar de un defensor público que le brinde asesoría especializada y lo represente durante la actuación estatal; c) opinar y que su parecer sea tomado en cuenta en todas las decisiones estatales; d) ser informado de las medidas de protección dispuestas a su favor, así como sobre la situación de los miembros de su familia y estado del procedimiento; e) solicitar la variación o remoción de la medida de protección; y, f) formular quejas o peticiones a la autoridad competente.

Debemos recordar que el reconocimiento del niño como sujeto de derechos es en la línea del tiempo de la evolución de los derechos de la infancia el punto de partida del cambio de la doctrina de la situación irregular a la doctrina de la protección integral que proclama la Convención sobre los Derechos del Niño, de tal forma que el niño deja de ser considerado como propiedad de sus padres u objeto de tutela por parte del Estado, para ser reconocido como un ser humano titular de derechos.

Este reconocimiento del niño como sujeto de derechos lo encontramos igualmente desarrollado en los artículos $14 .^{\circ}, 17 .^{\circ}$ y $20 .^{\circ}$ del Decreto Legislativo N. ${ }^{\circ} 1297$, al gozar el niño de los siguientes derechos: a) solicitar la actuación de diligencias, evaluaciones o presentar los documentos que considere pertinentes; b) comunicar la situación de riesgo o desprotección familiar en la que se encuentre, sin exigencia de requisito alguno; y, c) ser informado verbalmente del estado del procedimiento.

De otro lado, a la familia de origen del niño se le garantiza los siguientes derechos: a) ser informada de los alcances y desarrollo del procedimiento por riesgo o desprotección familiar; b) ser notificada de todas las decisiones que se tomen en el procedimiento, excepto aquellas de mero trámite o las dictadas para impulsar el procedimiento. c) mantener contacto con la niña, niño o adolescente; d) contar con un abogado que la asista en la defensa de sus intereses durante la actuación estatal; e) participar en la elaboración e implementación del plan de trabajo individual y que su opinión sea valorada por el equipo responsable de la evaluación de dicho plan; y, f) presentar los recursos impugnatorios a que hubiera lugar.

La participación activa de la familia es significativa, pues en atención a que lo que es materia de investigación es la presunta situación de riesgo o desprotección familiar de un niño, corresponde a la familia de origen coadyuvar al esclarecimiento de los hechos que hubieran dado lugar a la investigación, y, en su caso, contradecirla a efectos de propiciar la reintegración familiar.

\section{c) Medidas de protección en situaciones de riesgo:}

Conforme al artículo $27 .{ }^{\circ}$ del Decreto Legislativo N. ${ }^{\circ} 1297$ el procedimiento por riesgo tiene dos etapas: a) evaluación de la situación socio-familiar del niño; y, b) implementación del plan de trabajo individual orientado a modificar o neutralizar la situación de riesgo.

La primera etapa supone la obligación de la autoridad administrativa de identificar aquellos factores que podrían implicar riesgo para a un niño, a partir de lo cual decide abrir o no el respectivo procedimiento por riesgo.

De abrirse el aludido procedimiento, corresponde a la autoridad, entre otros, adoptar las medidas de urgencia para la atención de las necesidades inmediatas del niño, más aún si se declara la situación de riesgo provisional, en cuyo caso un equipo interdisciplinario, entendemos conforma- 
do por diversos profesionales (psicólogos, asistentas sociales y terapeutas familiares), procederá a diseñar el plan de trabajo indicado para el caso en concreto, el cual incluye las acciones de protección que resulten pertinentes.

El artículo $32 .^{\circ}$ establece las medidas de protección que pueden disponerse: a) apoyo a la familia para fortalecer competencias de cuidado y crianza; b) acceso a servicios de educación y salud para niñas, niños y adolescentes; c) acceso a servicios de atención especializada; d) apoyo psicológico a favor de la niña, niño o adolescente y su familia; e) acceso a servicios para prevenir y abordar situaciones de violencia; f) acceso a servicios de cuidado; g) acceso a servicios de formación técnico productivo para la, o el adolescente y su familia; h) inclusión a programas sociales; i) otras que fueran necesarias.

Como es de colegir, el legislador deja sentada la posibilidad de que se adopten otras medidas orientadas a salvaguardar la integridad y el efectivo ejercicio de los derechos de un niño, enfocándose la protección desde la perspectiva del fortalecimiento de la familia y satisfacción del bienestar e intereses del niño.

Al respecto, resulta oportuno resaltar que en relación a las medidas de protección a favor de un niño, las Directrices sobre las modalidades alternativas de cuidado de los niños establecen las siguientes pautas a ser observadas por los Estados:
I. Elaborar y aplicar políticas coherentes y mutuamente complementarias orientadas a la familia con objeto de promover y reforzar la capacidad de los padres para cumplir sus deberes de cuidado de sus hijos.

II. Aplicar medidas eficaces para prevenir el abandono de niños, la renuncia a la guarda y la separación del niño de su familia. En ese sentido, las políticas y programas sociales deben brindar a las familias los medios para adquirir la conciencia, las aptitudes, las capacidades y las herramientas que les permitan proveer debidamente a la protección, el cuidado y el desarrollo de sus hijos mediante medidas de protección sociales que comprendan lo siguiente:

a) Servicios de mejora del medio familiar, como la educación parental, el fomento de relaciones positivas entre los padres y los hijos, las técnicas de solución de conflictos, oportunidades de empleo y de generación de ingresos y, de ser necesario, asistencia social;

b) Servicios de apoyo social, como servicios de guardería, mediación y conciliación, tratamiento de la toxicomanía, ayuda económica y servicios para los padres e hijos que sufren algún tipo de discapacidad.

c) Políticas juveniles dirigidas a facultar a los jóvenes para hacer frente de una manera positiva a los desafíos de la vida cotidiana, en especial al decidir abandonar el hogar familiar, y a preparar a los futuros padres a adoptar decisiones fundamentadas con respecto a su salud sexual y reproductiva y a asumir sus responsabilidades a este respecto.

III.Preparar, ejecutar y evaluar las medidas de protección del niño con la participación de sus padres o tutores legales y la de sus guardadores y cuidadores familiares potenciales, tomando debidamente en consideración las necesidades particulares, creencias y deseos especiales del niño.

\section{CONCLUSIÓN:}

La norma en comento constituye un esfuerzo estatal innegable y acorde a los alcances de la Convención sobre los Derechos del Niño y de las Directrices sobre las modalidades alternativas de cuidado de los niños, pues conforme se expresa en el Preámbulo de la primera, la infancia tiene derecho a cuidados y asistencia especiales, pero a la vez la familia debe recibir la protección y asistencia necesarias para poder asumir plenamente sus responsabilidades dentro de la comunidad.

Por tanto, la intervención estatal debe estar orientada, en principio, a detectar en forma oportuna los casos de niños carentes de atención parental o que sufren maltratos, se encuentran expuestos a peligro, son inducidos a la mendicidad, etc; para efectos de determinar la existencia de una situación de riesgo que daría a su 
vez lugar al inicio de un procedimiento por desprotección familiar.

Ahora bien, la primera medida de protección considerada por la norma es el apoyo a la familia con la finalidad de fortalecer sus competencias de cuidado y crianza, pues la intención legislativa no es desarraigar al niño de su entorno familiar, sino, brindarle a los padres o responsables el soporte y la orientación profesional que requieran a fin que puedan superar en forma satisfactoria las causas que dieron lugar a la desprotección familiar.

Esto supone que la autoridad estatal se involucra con la familia a fin de brindarle oportunidades de superación de aquellas pautas de crianza negativas en clara realización de la protección especial que merece conforme al artículo $4 .^{\circ}$ de la Norma Fundamental.

Es importante destacar que la separación de un niño de su familia es una medida de última ratio, conforme así se desprende de los alcances del principio de necesidad; por tanto, la resolución judicial que declara la desprotección familiar, hecho que implica a la vez la pérdida del ejercicio de la patria potestad, debe ser una decisión meditada y responsable, pero sobre todo sustentada en el interés superior del niño, de allí que se haya considerado una audiencia especial, previa a la resolución judicial, para que la autoridad judicial escuche la opinión del niño respecto de los hechos que han dado lugar al procedimiento judicial, para lo cual es necesario que con un lenguaje claro, senci- llo y acorde a sus características particulares le informe de las implicancias de la decisión judicial.

Ahora solo queda esperar la expedición del Reglamento, por el cual se deberá, entre otros, precisar los supuestos de riesgo de desprotección familiar y desprotección familiar propiamente de un niño, así como los criterios de valoración objetivos para promover la declaración judicial de desprotección familiar, a mérito de lo cual corresponderá al Ministerio de la Mujer y Poblaciones Vulnerables, Ministerio de Justicia y Derechos Humanos, Ministerio Público, Poder Judicial y Policía Nacional del Perú actuar diligente y responsablemente en el marco de sus atribuciones para efectos de garantizar el interés superior del niño. 